\title{
Efficiency and rumen responses in younger and older Holstein heifers limit-fed diets of differing energy density ${ }^{1}$
}

\author{
G. I. Zanton ${ }^{*^{2}}$ and A. J. Heinrichst \\ *USDA-Agricultural Research Service, US Dairy Forage Research Center, Madison, WI 53706 \\ †Department of Animal Sciences, The Pennsylvania State University, University Park 16802
}

\begin{abstract}
The objective of this study was to evaluate the effects of limit feeding diets of different predicted energy density on the efficiency of utilization of feed and nitrogen and rumen responses in younger and older Holstein heifers. Eight rumen-cannulated Holstein heifers (4 heifers beginning at $257 \pm 7 \mathrm{~d}$, hereafter "young," and 4 heifers beginning at $610 \pm 16 \mathrm{~d}$, hereafter "old") were limit-fed high [HED; $2.64 \mathrm{Mcal} / \mathrm{kg}$ of dry matter (DM), $15.31 \%$ crude protein (CP)] or low (LED; $2.42 \mathrm{Mcal} /$ $\mathrm{kg}$ of DM, $14.15 \% \mathrm{CP}$ ) energy density diets according to a 4-period, split-plot Latin square design with 28 -d periods. Diets were limit-fed to provide isonitrogenous and isoenergetic intake on a rumen empty body weight (BW) basis at a level predicted to support approximately $800 \mathrm{~g} / \mathrm{d}$ of average daily gain. During the last $7 \mathrm{~d}$ of each period, rumen contents were subsampled over a 24-h period, rumen contents were completely evacuated, and total collection of feces and urine was made over $4 \mathrm{~d}$. Intakes of DM and water were greater for heifers fed LED, although, by design, calculated intake of metabolizable energy did not differ between age groups or diets when expressed relative to rumen empty BW. Rumen pH was lower, ammonia $\left(\mathrm{NH}_{3}-\mathrm{N}\right)$ concentration tended to be higher, and volatile fatty acids (VFA) concentration was not different for HED compared with LED and was unaffected by age group. Rumen content mass was greater for heifers fed LED and for old heifers, so when expressing rumen fermentation responses corrected for this difference in pool size, $\mathrm{NH}_{3}-\mathrm{N}$ pool size was not different between diets and total moles of VFA in the rumen were greater for heifers fed LED, whereas these pool sizes were greater for old heifers. Total-tract digestibility of potentially digestible neutral detergent fiber (NDF) was greater
\end{abstract}

Received August 26, 2015.

Accepted December 11, 2015.

${ }^{1}$ Mention of any trademark or proprietary product in this paper does not constitute a guarantee or warranty of the product by the USDA or the Agricultural Research Service and does not imply its approval to the exclusion of other products that also may be suitable.

${ }^{2}$ Corresponding author: geoffrey.zanton@ars.usda.gov in heifers fed LED and for young heifers, whereas the fractional rate of ruminal passage and digestion of NDF were both greater in heifers fed LED. Digestibility of $\mathrm{N}$ was greater for heifers fed HED, but was unaffected by age group, whereas the efficiency of $\mathrm{N}$ retention was greater for heifers fed HED and for young heifers. Manure output was reduced in heifers fed HED, but the effect was largest in old heifers. Results confirm previous studies in which young heifers utilize $\mathrm{N}$ more efficiently than old heifers, primarily through greater efficiency of postabsorptive metabolism. Results also support the concept of limit feeding HED diets as a potential means to reduce manure excretion and increase nitrogen efficiency.

Key words: dairy heifer, limit feeding, efficiency

\section{INTRODUCTION}

Dairy cattle production efficiency depends on multiple factors associated with the nutrition, reproduction, management, and genetics of the lactating cows. Additionally, the heifer-rearing program has a significant effect on whole-farm production efficiency (Tozer and Heinrichs, 2001). For instance, lifetime feed efficiency (cumulative milk production/cumulative DMI) does not exceed 1 until toward the end of the first lactation using realistic assumptions (i.e., from the NRC, 2001) on heifer DMI, ADG, lactation DMI, and milk production. Opportunities exist to increase the nutritional efficiency of raising heifers from birth to calving using limit feeding of higher energy density diets to meet but not exceed energy requirements for an optimal level of ADG. Managing dairy heifer nutrition over a range of diets and with a range of heifer ages with limit feeding has shown that heifers can maintain a similar level of structural growth (Zanton et al., 2007; Lascano et al., 2008), have increased feed efficiency (ADG:DMI; Zanton and Heinrichs, 2007; Hoffman et al., 2007), reduced excreta output (Moody et al., 2007; Lascano et al., 2008), and similar levels of milk production in the first lactation (Zanton and Heinrichs, 2010). To apply limit feeding on-farm requires more intensive management of the dairy heifer housing and nutrition than is typi- 
cally practiced using conventional heifer management and feeding practices. Additionally, negative changes in rumen fermentation could be anticipated depending on the energy density of the diet and feeding management.

Application of limit feeding has been studied in pre- and postpubertal dairy heifers in different studies; however, little data exist that would guide recommendations across these groups where a common diet was fed. Moody et al. (2007) found that when corn silage was the sole forage, low corn silage diets that were limit-fed to 6- or 12-mo-old Holstein heifers were utilized more efficiently than the high corn silage diets. Dry matter digestibility tended to be improved for the older heifers, although the efficiency of $\mathrm{N}$ retention tended to be improved for younger heifers. Zanton and Heinrichs (2008) determined that nitrogen retention was affected by an interaction between $\mathrm{BW}, \mathrm{ME}$ intake, and $\mathrm{N}$ intake, wherein a decline in $\mathrm{N}$ retention [g of $\mathrm{N} /$ $\mathrm{kg}$ of metabolic BW $\left(\mathrm{BW}^{0.75}\right)$ ] occurred with increasing animal BW and this decline was greater for animals with a higher energy intake. This confirmed previous work by Blaxter et al. (1966), in which it was determined that the efficiency of $\mathrm{N}$ retention declined with age in 3 growing Ayrshire steers fed a common diet at 3 different levels of intake.

Limiting intake and reducing the level of forage in the diet would be predicted to decrease rate of passage of feed from the rumen, potentially increasing diet digestibility in the rumen (Colucci et al., 1990; NRC, 2001). These dietary changes would also be predicted to increase rumen digestibility because of the higher proportion of more fermentable feedstuffs. Possibly counterbalancing these effects would be an expected decrease in rumen $\mathrm{pH}$ due to the greater energy density of the diet, thus resulting in a decrease in the rate of digestion (Mould et al., 1983; Grant and Mertens, 1992). Given the possible interactions among these different factors, the effects of limit feeding higher or lower digestibility diets to younger and older dairy heifers is unknown. Therefore, the objective of this study was to evaluate the effects of limit feeding diets of different predicted energy density on the efficiency of utilization of feed and nitrogen and the rumen responses in younger and older Holstein heifers. Our hypothesis was that limit feeding diets of different energy densities to dairy heifers would change nutritional efficiency and affect rumen fermentation.

\section{MATERIALS AND METHODS}

\section{Animals and Treatments}

To accomplish the objective of this experiment, 8 nonpregnant Holstein heifers were selected from the Penn
State dairy herd based on selection criteria for age and BW. The use of animals and all procedures involving the use of animals were approved by the Pennsylvania State University Institutional Animal Care and Use Committee. Heifers selected were classified as younger (hereafter "young" heifers; $257 \pm 7 \mathrm{~d}$ old and $221 \pm 9$ $\mathrm{kg}$ of $\mathrm{BW}$ at the initiation of the experiment; mean \pm SD) or older (hereafter "old" heifers; $610 \pm 16 \mathrm{~d}$ old and $537 \pm 16 \mathrm{~kg}$ of BW at the initiation of the experiment; mean $\pm \mathrm{SD}$ ). Heifers were surgically prepared with a rumen cannula under local anesthesia at least 2 mo before the initiation of sample collection (rumen cannulas were either 10.16 or $7.62 \mathrm{~cm}$ i.d. for old and young heifers, respectively). Heifers were housed in individual tiestalls in a mechanically ventilated barn for the duration of the experiment except on days on which sampling was not conducted, when heifers were allowed access to a paved exercise lot for approximately $2 \mathrm{~h}$ before the morning feeding.

Feed was mixed once daily (Super Data Ranger, American Calan, Northwood, NH) at approximately $1500 \mathrm{~h} ; 50 \%$ of the daily allotment was delivered fresh at $2000 \mathrm{~h}$ and $50 \%$ was stored in refrigeration overnight for feeding at $0800 \mathrm{~h}$ the next morning. Treatment diets were formulated to be lower or higher in predicted energy density (LED or HED, respectively; Table 1). Corn silage DM was determined thrice weekly to adjust the as-fed diet mixture; additionally, water was added to HED as needed to lower the formulated ration DM to $65 \%$ to reduce dustiness. Treatment diets were formulated to provide an equal amount of predicted $\mathrm{ME}$ and CP per rumen empty metabolic BW $\left(\mathbf{R E B W}^{0.75}\right)$, where REBW was calculated from measured full BW and measured rumen content weight (ME and CP prediction based on NRC, 2001 at a level to support $\sim 800$ $\mathrm{g} / \mathrm{d}$ of ADG). On the day before initiation of the experiment and every $14 \mathrm{~d}$ thereafter, heifers were weighed before the morning and evening feeding and had rumen contents evacuated, weighed, and subsampled at the midpoint between feedings $(1400 \mathrm{~h})$; these data were used to allocate the feed DM offered for the subsequent $14 \mathrm{~d}$.

\section{Experimental Design and Sample Collection}

Experiment was designed as a split-plot, 4-sequence, 4-period changeover design to account for the potential for carryover effects of previous treatment (design 4.4.13 from Jones and Kenward, 2003). In this design, heifer age category was the whole plot and nutritional treatments applied according to a crossover design were the subplots. Periods were $28 \mathrm{~d}$ in length, with the first $21 \mathrm{~d}$ for adaptation and the last $7 \mathrm{~d}$ for sampling. Feed and refusal (if any) samples were collected daily and 
composited by period. On d 21 to 22 of each period, rumen samples from the dorsal, caudal, and ventral areas of the rumen were removed at the following times relative to morning feeding on $\mathrm{d} 21: 0,1,2,3,4,6$, $8,10,12,14,18,22$, and $24 \mathrm{~h}$. Whole rumen samples were mixed by hand and squeezed through 4 layers of cheesecloth before immediately analyzing rumen fluid for $\mathrm{pH}$ ( $\mathrm{pH}$ meter, model M90, Corning Inc., Corning, $\mathrm{NY}$ ). A $15-\mathrm{mL}$ subsample was stored at $-20^{\circ} \mathrm{C}$ with $3 \mathrm{~mL}$ of $25 \%$ metaphosphoric acid and with $3 \mathrm{~mL}$ of $0.6 \%$ 2-ethyl butyric acid as an internal standard. On d 22 of each period, heifers were urinary catheterized (\#14 French balloons, Rusch Inc., Duluth, GA) before feeding for a 4-d total collection of urine and feces. Urine was collected continuously into a 25 -L container, which was maintained at $\mathrm{pH}<3$ by the addition of 12 $N \mathrm{HCl}$. Urine and feces were weighed daily immediately after morning feeding, and a representative subsample was removed for subsequent analysis. As stated previ-

Table 1. Ingredient and chemical composition (\% of DM unless otherwise noted) of higher energy density (HED) and lower energy density (LED) treatment diets limit fed to younger and older Holstein heifers

\begin{tabular}{|c|c|c|c|}
\hline Item & HED & LED & $\mathrm{SE}$ \\
\hline \multicolumn{4}{|l|}{ Ingredient composition } \\
\hline Grass hay & 12.8 & 3.0 & \\
\hline Alfalfa hay & 2.0 & 35.0 & \\
\hline Corn silage & 9.4 & 36.2 & \\
\hline Ground corn & 57.0 & 14.7 & \\
\hline Soybean meal & 7.0 & 3.9 & \\
\hline Cottonseed hulls & 4.9 & 2.0 & \\
\hline Urea & 0.93 & 0.05 & \\
\hline Sodium bicarbonate & 0.96 & 0.99 & \\
\hline Mineral mix & $5.2^{1}$ & $4.0^{2}$ & \\
\hline \multicolumn{4}{|l|}{ Chemical composition } \\
\hline DM, $\%$ as fed & 67.6 & 58.1 & 0.4 \\
\hline $\mathrm{OM}$ & 94.5 & 94.2 & 0.3 \\
\hline $\mathrm{CP}$ & 15.3 & 14.2 & 0.1 \\
\hline Soluble $\mathrm{CP}, \%$ of $\mathrm{CP}$ & 36.6 & 37.1 & 0.4 \\
\hline $\mathrm{NDF}$ & 26.3 & 37.3 & 0.2 \\
\hline Forage NDF & 14.1 & 33.2 & 0.2 \\
\hline Potentially digestible NDF & 18.1 & 23.2 & 0.5 \\
\hline Indigestible NDF & 8.1 & 14.1 & 0.4 \\
\hline $\mathrm{ADF}$ & 16.5 & 27.1 & 0.5 \\
\hline Starch & 43.3 & 26.1 & 0.3 \\
\hline $\mathrm{Ca}$ & 0.72 & 1.11 & 0.04 \\
\hline $\mathrm{P}$ & 0.33 & 0.30 & 0.01 \\
\hline $\mathrm{Na}$ & 0.22 & 0.29 & 0.01 \\
\hline $\mathrm{K}$ & 0.96 & 1.19 & 0.01 \\
\hline
\end{tabular}

${ }^{1}$ HED mineral contained (\% DM basis) corn distillers grains with solubles, 45.4; potassium chloride, 21.1; limestone, 19.2; salt, 7.7; potassium magnesium sulfate, 3.1; magnesium oxide, 1.5; sodium selenite $0.06 \%, 0.9$; trace mineral premix $(\mathrm{Cu}, 40,816 \mathrm{mg} / \mathrm{kg} ; \mathrm{Fe}, 10,204 \mathrm{mg} /$ $\mathrm{kg}$; Mn, 122,450 mg/kg; Zn, 122,450 mg/kg), 0.8; ADE (30,000 kIU of vitamin $\mathrm{A} / \mathrm{kg}, 7,250 \mathrm{kIU}$ of vitamin $\mathrm{D} / \mathrm{kg}$, and $180 \mathrm{kIU}$ of vitamin $\mathrm{E} / \mathrm{kg}), 0.4$.

${ }^{2}$ LED mineral contained (\% DM basis) corn distillers grains with solubles, 64.5; limestone, 15.8; salt, 15.8; sodium selenite $0.06 \%, 1.7$; trace mineral premix $(\mathrm{Cu}, 40,816 \mathrm{mg} / \mathrm{kg} ; \mathrm{Fe}, 10,204 \mathrm{mg} / \mathrm{kg} ; \mathrm{Mn}, 122,450$ $\mathrm{mg} / \mathrm{kg} ; \mathrm{Zn}, 122,450 \mathrm{mg} / \mathrm{kg}), 1.4 ; \mathrm{ADE}(30,000 \mathrm{kIU}$ of vitamin $\mathrm{A} / \mathrm{kg}$, $7,250 \mathrm{kIU}$ of vitamin $\mathrm{D} / \mathrm{kg}$, and $180 \mathrm{kIU}$ of vitamin $\mathrm{E} / \mathrm{kg}), 0.8$. ously, on d 14 and 28 of each period beginning $6 \mathrm{~h}$ after morning feeding, the contents of the reticulo-rumen were removed. Immediately before evacuation, access to feed and water was removed. Rumen contents were weighed, mixed thoroughly, and subsampled before replacing the remaining contents into the rumen of each heifer and restoring access to feed and water. During wk 2 of adaptation in periods 2 and 4,4 heifers that remained on the same diet as in periods 1 and 3 were used to incubate corn silage in situ. Corn silage for the in situ trial was dried for $48 \mathrm{~h}$ at $55^{\circ} \mathrm{C}$ in a forced-air oven and ground to pass through a 2-mm screen (Wiley mill, Arthur H. Thomas, Philadelphia, PA); then, $5 \mathrm{~g}$ of the sample was weighed into each bag. After soaking for $15 \mathrm{~min}$ in $39^{\circ} \mathrm{C}$ distilled water, bags $(10 \times 20 \mathrm{~cm}$, $53-\mathrm{mm}$ pore size) were incubated in the ventral rumen in reverse order for $1,2,4,8,16,24,48$, and $72 \mathrm{~h}$ and removed simultaneously at $4 \mathrm{~h}$ after morning feeding on d 12 of these periods. Rumen contents were removed from the exterior of the bags manually, before machine washing in cold water 3 times for a 2-min cycle each. Time points within each heifer-period unit were replicated in quadruplicate. Bags were dried at $55^{\circ} \mathrm{C}$ for 48 $\mathrm{h}$, weighed, and composited by heifer-period-time point for chemical analysis.

\section{Chemical Analysis}

Composited feed and refusal samples were dried in a forced air oven at $55^{\circ} \mathrm{C}$ for $48 \mathrm{~h}$, and ground through a 1-mm screen (Wiley mill, Arthur H. Thomas) and period-composited samples were analyzed for DM, ash, and CP (Association of Official Analytical Chemists, 1990), soluble protein (Krishnamoorthy et al., 1982), NDF and ADF (Van Soest et al., 1991), and starch (Bach Knudsen, 1997; as modified in Zanton and Heinrichs, 2009a), with mineral analysis conducted at Cumberland Valley Analytical Services (Hagerstown, MD). Analysis of NDF included use of heat-stable $\alpha$-amylase and sodium sulfite (Van Soest et al., 1991) with analysis modified for the Ankom ${ }^{200}$ Fiber Analyzer (Ankom Technology Corporation, Fairport, NY). Feed N was analyzed on dried samples, and fecal and urine $\mathrm{N}$ were analyzed on wet samples by the Kjeldahl method (Association of Official Analytical Chemists, 1990). Composited in situ samples were also ground and analyzed for NDF in a manner consistent with that used for feed samples. Evacuated rumen content samples were stored at $-20^{\circ} \mathrm{C}$ until freeze-drying, grinding, and subsequent chemical analysis in a manner similar to that used for feed. Indigestible NDF (iNDF) was determined in feces and evacuated rumen contents using the procedure detailed in Maulfair et al. (2011), and rumen NDF kinetics were calculated using the procedure reported 
by Dado and Allen (1995). Potentially digestible NDF (pdNDF) intake is the calculated difference between total NDF intake and iNDF excreted; excretion of pdNDF is the difference between total NDF excreted and iNDF excreted; and pdNDF in rumen contents is the difference between total NDF in evacuated rumen contents and iNDF in evacuated rumen contents. Thawed rumen fluid samples were centrifuged 3 times at $4,000 \times g$ for $30 \mathrm{~min}$ at $4^{\circ} \mathrm{C}$, and the clear supernatant was retained for analysis. The supernatant was analyzed for rumen $\mathrm{NH}_{3}-\mathrm{N}$ according to Chaney and Marbach (1962) and for molecular concentration of VFA by GC (Yang and Varga, 1989). Weighted average responses of concentrations of rumen metabolites were calculated using the area under the curve calculated according to the trapezoidal rule. Pool sizes of VFA and ammonia were estimated by multiplying the weighted average concentrations from the time course samples and the mass lost on drying from the rumen evacuation on period d 28. Proportion of time between morning and evening feeding with $\mathrm{pH}<6.0$ (based on the reduction of fiber digestion that occurs around this $\mathrm{pH}$; Mould et al., 1983) was calculated by interpolating the time between samplings at which the $\mathrm{pH}$ went below or above 6.0, summing the hours $<6.0$, and dividing by 12 . On $2 \mathrm{~d}$ per period, feces and unacidified, chilled $\left(4^{\circ} \mathrm{C}\right)$ urine were subsampled from 4 heifers (1 observation per heifer per period) and ammonia volatilization was analyzed using a bench-top, steady-state (dynamic) flux chamber under laboratory conditions, as detailed by Lascano et al. (2008).

\section{Statistical Analysis}

Data were analyzed as a split-plot, crossover design where the whole-plot factor was the age category of the heifers and the subplot factor was dietary treatment provided according to a 2-treatment, 4-period, 4 -sequence crossover design so that every treatment followed every treatment an equal number of times (design 4.4.13 from Jones and Kenward, 2003). Statistical analysis was conducted using the mixed procedure of SAS Institute (2013). Fixed-effect factors included in the statistical model were period, age category, diet, the interaction between age and diet, and the residual effect of previous treatment. Random effect was heiferwithin-age category. The effect of previous treatment was not determined to be significant for any of the responses except for BW gain. For responses in which multiple observations occurred within a period, the fixed effect of time and fixed-effect interactions with time were included in the statistical analysis. Correlation between residuals was modeled using the first-order autoregressive covariance structure when multiple observations were made over time within heifer within period. The effect of age category was evaluated with the denominator degrees of freedom and the error term associated with whole-plot error of heifer(age category), whereas the effect of dietary treatment and the interaction were evaluated against the pooled residual error. Analysis of corn silage in situ response profiles were conducted according to the method reported in Zanton and Heinrichs (2009b) except that the NLMixed procedure was used. Least squares means are presented in tables and evidence for statistical significance was declared at $P<0.05$ and tendency toward significance at $0.05<P<0.10$.

\section{RESULTS}

To change dietary energy density in this study, HED contained lower concentrations of NDF and higher concentrations of starch compared with LED (Table 1). By design, due to the objective of providing comparable intakes of energy and protein through limit-feeding DMI, the CP concentration was higher for HED in an attempt to maintain isonitrogenous intakes. Feed was delivered to heifers to provide an equal intake of ME across rations and ages by feeding according to $\mathrm{REBW}^{0.75}$ and ME (Mcal) predicted according to feed composition (NRC, 2001). Observed ME intake (based on nutrient composition using NRC, 2001 predictions) did not differ between dietary treatments, and ME intake/REBW ${ }^{0.75}$ did not differ between age or diet groups (Table 2). Although full BW was greater for LED than for $\mathrm{HED}$, this was primarily due to differences in gut fill because REBW was not different between diets. Full BW gain per $28 \mathrm{~d}$ tended to be greater for heifers fed LED; however, REBW gain was not different by diet. The main effect of age and the interaction of diet and age were not significant for either effect. Because of the greater energy density of HED and no differences in ME intake, DMI was lower for heifers fed HED than for heifers fed LED. Voluntary and total water intake were also lower for heifers fed HED, although this was explained by more than just the reduced DMI because the ratio of water intake to DMI was different between diets but not for heifers of different ages.

Through the combined effects of lower NDF and higher starch concentrations, HED diets resulted in lower mean $\mathrm{pH}$ and a tendency toward lower maximum and minimum rumen $\mathrm{pH}$ (Table 3). The HED diet also resulted in a higher proportion of time below pH 6.0. Mean rumen $\mathrm{NH}_{3}$ concentration tended to be higher for heifers fed HED than for heifers fed LED, whereas maximum and minimum rumen $\mathrm{NH}_{3}$ concentrations were greater and the proportion of time $<5 \mathrm{mg} /$ dL was lower for heifers fed HED. Total rumen VFA 
concentrations were not affected by dietary treatment although a greater proportion of the VFA was acetate for LED and propionate and butyrate for HED. Rumen metabolite concentrations were not affected by the age group of the heifers. The circadian profile of these rumen metabolites is shown in Figure 1. Whole rumen contents had greater mass for heifers fed LED than for heifers fed HED on an absolute basis and as a ratio to REBW (Table 4). Likewise, older heifers had a greater whole-rumen content mass than younger heifers on an absolute basis and as a ratio to REBW. We detected no differences between diets or age groups related to total feed and water consumption. For all other chemical component pool sizes evaluated, heifers fed LED and old heifers had greater masses than HED and young heifers, respectively. When scaled to the daily consumption of the appropriate chemical component, the effect of age was no longer significant and diet was no longer significant for rumen DM or liquid. For NDF, pdNDF, and iNDF pool sizes, scaling to the daily consumption of the chemical component resulted in greater turnover times for HED compared with LED. Adjusting $\mathrm{pH}, \mathrm{NH}_{3}-\mathrm{N}$, and VFA for rumen liquid pool size led to different inferences about treatment responses than from the concentrations; in particular, the pool sizes of $\mathrm{NH}_{3}-\mathrm{N}$ and VFA were greater for old heifers than for young heifers, $\mathrm{NH}_{3}-\mathrm{N}$ pool size did not differ between diets, and total VFA pool size was greater in LED than in HED.

Chemical component consumption and digestion are shown in Table 5. Although NDF and starch intake were different between diets, digested OM was not different between diets due to the limitation placed on DMI in both diets. Digestibility of NDF tended to be greater for heifers fed HED than for those fed LED, but when accounting for the greater consumption of iNDF in LED, digestibility of pdNDF was greater for heifers fed LED. Interestingly, digestibility of pdNDF was greater for young heifers than for old heifers, whereas the reverse tended to be observed for starch. Parameter estimates for in situ corn silage disappearance were generally not different for OM and NDF disappearance (Table 6). The exception to this was for the lag parameter estimate, where young heifers fed HED had a higher lag time and old heifers fed HED had a lower lag time than the heifers from either age group fed LED, which did not differ from each other. Based on iNDF as an internal marker, the fractional rate of NDF passage from the rumen and the fractional rate of NDF digestion were greater for heifers fed LED than for heifers fed HED (Table 7). These differences in competing factors of digestion and passage resulted in no significant differences in calculated apparent pdNDF digestibility in the rumen, although heifers fed LED had a lower proportion of total-tract digestion occurring in the rumen, indicating compensatory digestibility of pdNDF at postruminal sites in the digestive tract. Age group did not affect any pdNDF digestion kinetic response.

Intake of $\mathrm{N}$ and apparent digested $\mathrm{N}$ intake were greater for heifers fed HED than LED (Table 8). Because fecal $\mathrm{N}$ excretion tended to be greater for heifers fed HED and urine $\mathrm{N}$ excretion was not different, total

Table 2. Descriptive and intake characteristics of young or old heifers limit-fed diets with high (HED) or low energy density (LED)

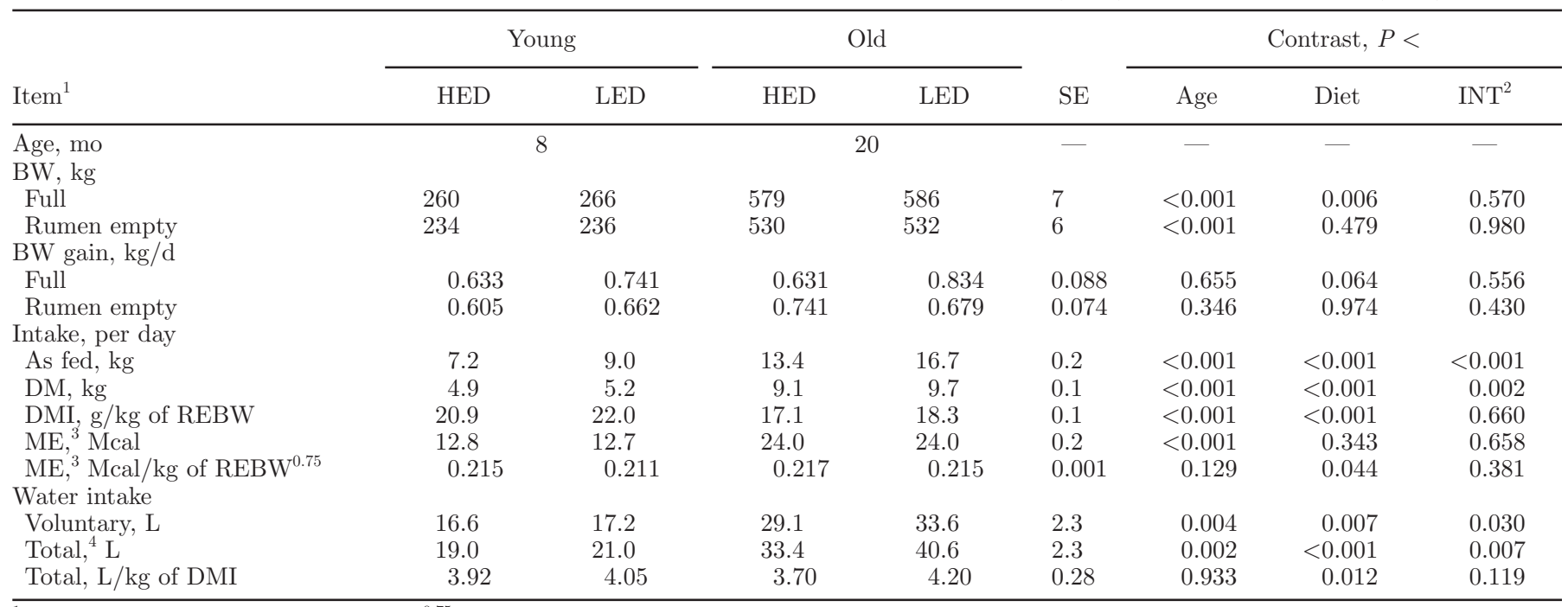

${ }^{1} \mathrm{REBW}=$ rumen empty BW; REBW ${ }^{0.75}=$ rumen empty metabolic BW.

${ }^{2}$ Interaction between age and diet main effects.

${ }^{3}$ Predicted based on ingredient composition, observed intake, and BW (NRC, 2001).

${ }^{4}$ Total water is the sum of that voluntarily consumed and lost from feed upon drying. 
$\mathrm{N}$ excretion was not affected by diet, and $\mathrm{N}$ retention was greater for heifers fed HED. The amount of $\mathrm{N}$ consumed and distributed to feces and urine was greater for old heifers than for young heifers, although $\mathrm{N}$ retention did not differ between age groups. Thus, the efficiency of retaining consumed or digested $\mathrm{N}$ was greater for young heifers than for old heifers, whereas apparent digestibility was not different between age groups but was greater for HED than for LED. Overall, daily $\mathrm{NH}_{3}$ volatilization was lower for heifers fed HED than LED and for young compared with old heifers. Heifers fed HED and young heifers excreted less $\mathrm{N}$ and had less $\mathrm{NH}_{3}$ volatilization to retain an equivalent amount of $\mathrm{N}$ compared with heifers fed LED and old heifers. Heifers fed HED had lower outputs of wet feces and urine compared with heifers fed LED (Table 9). This response was driven by the excretion of liquid waste, primarily with feces.

\section{DISCUSSION}

The heifer-rearing program and nutrition in particular are significant contributors to whole-farm expenses (Heinrichs et al., 2013). Nutritional management practices to improve the economic and environmental efficiency of raising dairy heifers from weaning through parturition should ultimately lead to improved wholefarm milk production efficiency if there are not detrimental changes in lactation performance (Zanton and Heinrichs, 2005). Dietary changes, especially those that alter dietary energy density, must also be amenable to maintaining optimal body condition and rumen health. Metabolic responses to nutritional manipulation imposed in this study would be predicted to be different based on literature analyses; however, few experimental data are available that have fed significantly different diets to different age dairy heifers at the same time as an experimental factor.

Given that the objective of the experiment was also to evaluate the effects of limit feeding, defining the amount of feed offered for diets of differing energy density across age groups is important. In this study, HED and LED diets were offered to young and old heifers to provide equal $\mathrm{ME}$ and $\mathrm{N}$ intakes on a $\mathrm{REBW}^{0.75}$ basis (predicted based on chemical composition and at a level predicted to support $\sim 800 \mathrm{~g} / \mathrm{d}$ of ADG; NRC, 2001; Zanton and Heinrichs, 2007). This decision was made in the attempt to meet the postabsorptive metabolic requirements for $\mathrm{ME}$ and MP across age groups without the interference of the potentially confounding effect of gut-fill differences across diets of differing energy density and to attempt to maintain a similar metabolic mass within age group. These expected differences in rumen content mass were realized; however, REBW was not different between diets as planned. Actual full BW gain and REBW gain were lower than predicted; however, caution should be exercised in interpreting gains in this crossover study with short period durations. Nevertheless, REBW gain was not different between heifers fed the different diets, and $\mathrm{ME}$

Table 3. Rumen metabolite concentrations for young or old heifers limit-fed diets with high (HED) or low energy density (LED) ${ }^{1}$

\begin{tabular}{|c|c|c|c|c|c|c|c|c|}
\hline Item & \multicolumn{2}{|c|}{ Young } & \multicolumn{2}{|c|}{ Old } & SE & \multicolumn{3}{|c|}{ Contrast, $P<$} \\
\hline \multicolumn{9}{|l|}{$\mathrm{pH}$} \\
\hline Maximum & 6.87 & 7.04 & 6.94 & 7.05 & 0.10 & 0.781 & 0.055 & 0.631 \\
\hline Minimum & 5.86 & 5.84 & 5.73 & 6.06 & 0.18 & 0.858 & 0.053 & 0.039 \\
\hline$<6.0, \%^{3}$ & 24.9 & 18.0 & 37.4 & 12.9 & 11.1 & 0.798 & 0.013 & 0.135 \\
\hline Maximum & 29.3 & 24.0 & 30.5 & 24.1 & 1.7 & 0.758 & $<0.001$ & 0.666 \\
\hline Minimum & 4.08 & 2.55 & 3.79 & 2.35 & 0.57 & 0.735 & 0.005 & 0.924 \\
\hline$<5.0, \%^{3}$ & 23.7 & 37.7 & 30.7 & 41.9 & 6.5 & 0.550 & $<0.001$ & 0.598 \\
\hline VFA, $\mathrm{m} M$ & 104 & 107 & 104 & 105 & 7 & 0.936 & 0.110 & 0.494 \\
\hline \multicolumn{9}{|c|}{ Individual VFA, mol/100 mol of VFA } \\
\hline Acetate & 62.4 & 66.4 & 62.3 & 68.2 & 0.7 & 0.407 & $<0.001$ & 0.050 \\
\hline Propionate & 19.4 & 19.3 & 18.8 & 16.9 & 1.0 & 0.290 & 0.041 & 0.047 \\
\hline
\end{tabular}

${ }^{1}$ Least squares means for fermentation responses for sampling times between morning and evening feedings; mean values calculated as the area under the response curve/12 h.

${ }^{2}$ Interaction between age and diet main effects.

${ }^{3}$ Calculated as hours that response was less than the indicated value/12 $\mathrm{h}$. 
intake also did not differ, from which we can infer that the energy status of these heifers limit-fed HED or LED was not detectibly different.
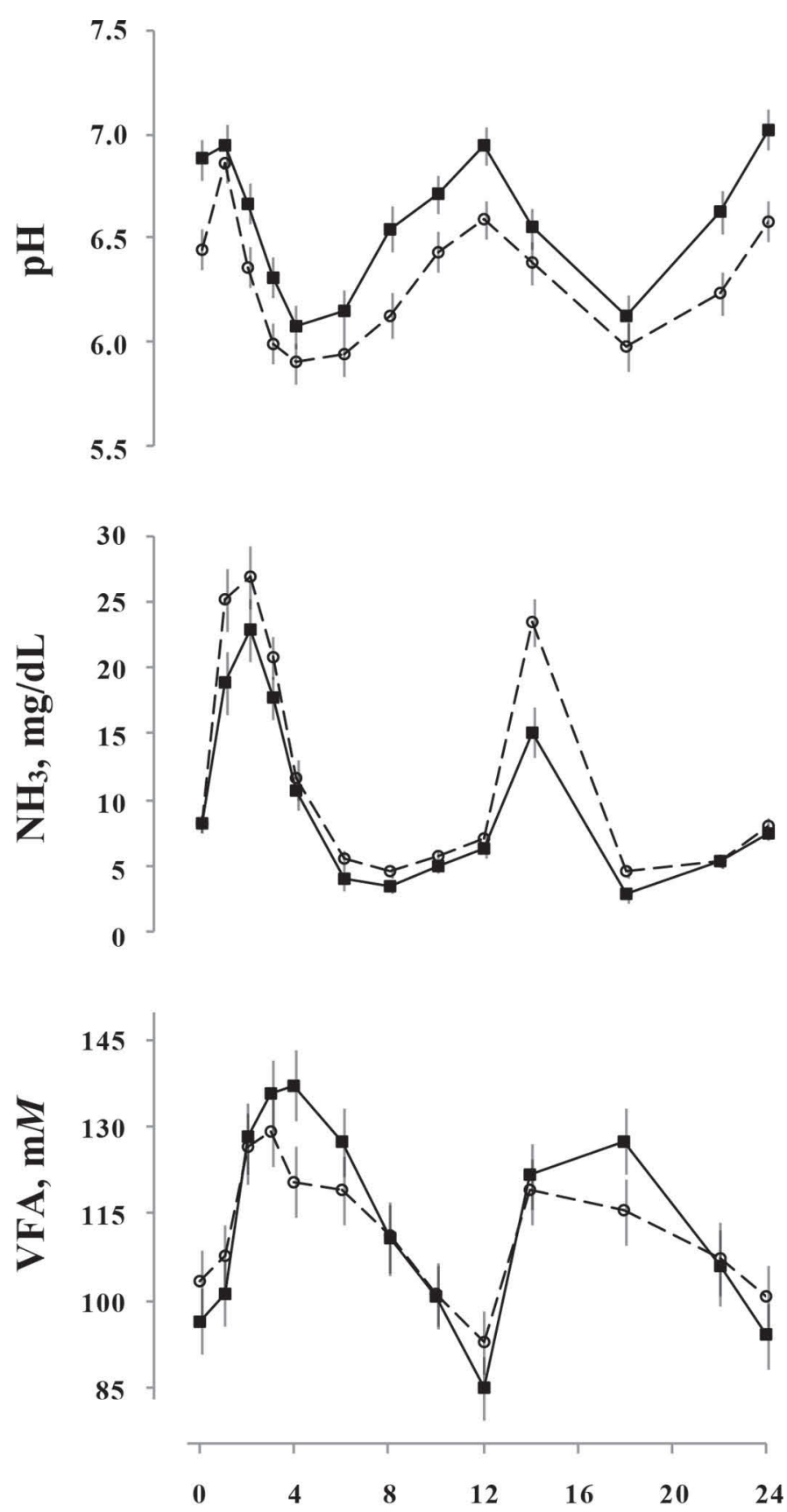

\section{Time after morning feeding, $h$}

Figure 1. Changes in $\mathrm{pH}, \mathrm{NH}_{3}$, and VFA concentration for heifers limit-fed diets with low $(\mathbf{\square})$ or high energy density $(\bigcirc)$; age effects and interaction between age and diet were not significant; diet by hour interaction was significant $(P<0.05)$ for each concentration. Error bars indicate the standard error.
Similarities in ME and $\mathrm{N}$ intakes were achieved by limiting the intake of the different energy density dietary treatments. Our strategy for formulating HED and LED was to approach each energy density treatment as a unique formulation using the same ingredients. The conditions that the diets had to meet were that ME and $\mathrm{N}$ intake could be restricted to a level that was equal across diets, fed at a level to meet predicted gain targets, without refusals, and across age categories. Intake limitation imposed on the heifers averaged $67.6 \%$ (old, HED), $75.1 \%$ (young, HED), $70.2 \%$ (old, LED), and $79.1 \%$ (young, LED) of NRC (2001)-predicted DMI. Dietary treatments in this experiment were therefore the combined effect of dietary composition and level of intake, which were predetermined based on predictions of energy conversion and requirement (NRC, 2001).

As expected, the HED diet had a greater total-tract OM digestibility, consistent with the dietary treatment assignments. As shown previously with dairy heifers (Zanton and Heinrichs, 2009a), digestibility of carbohydrate-based dietary components is depressed for HED, with the greater dietary OM digestibility due to the greater contribution of the higher digestibility feedstuffs in the HED diets. Total-tract digestibility of pdNDF was greater in young heifers compared with old heifers and it appears to be driven primarily due to differences in rumen pdNDF digestibility, although these differences were not significant. The reason for this response is not readily evident from the response data collected in this study; $\mathrm{pH}$ and $\mathrm{NH}_{3}$ concentrations were not different between age groups, and DMI was greater on a BW basis for young heifers that would be predictive of greater rate of passage from the rumen. However, rumen kinetics were not affected by age, and in situ NDF parameter estimates are not suggestive of greater digestibility for young heifers. Total-tract NDF digestibility tended to be greater for heifers fed the HED diet as has been shown in several studies in which HED diets are limit-fed compared with LED diets (Reynolds et al., 1991; Murphy et al., 1994); however, this was not due to increased digestive efficiency for the heifers in this study, but (consistent with the total diet) rather because of a greater concentration of pdNDF in total NDF for HED (LED had a higher concentration of iNDF). These results for the total diet and for NDF again highlight the importance of appropriately fractionating the ingested chemical components when using different feedstuff compositions that may also interact with the ability of the animal or rumen microbial community to digest these chemical components (Waldo et al., 1972; Allen and Mertens, 1988).

Rumen $\mathrm{pH}$ was lower for HED and the molar proportions of VFA were generally reflective of those expected on an HED brought on by increasing dietary ferment- 
Table 4. Rumen content pool sizes for young or old heifers limit-fed diets with high (HED) or low energy density (LED)

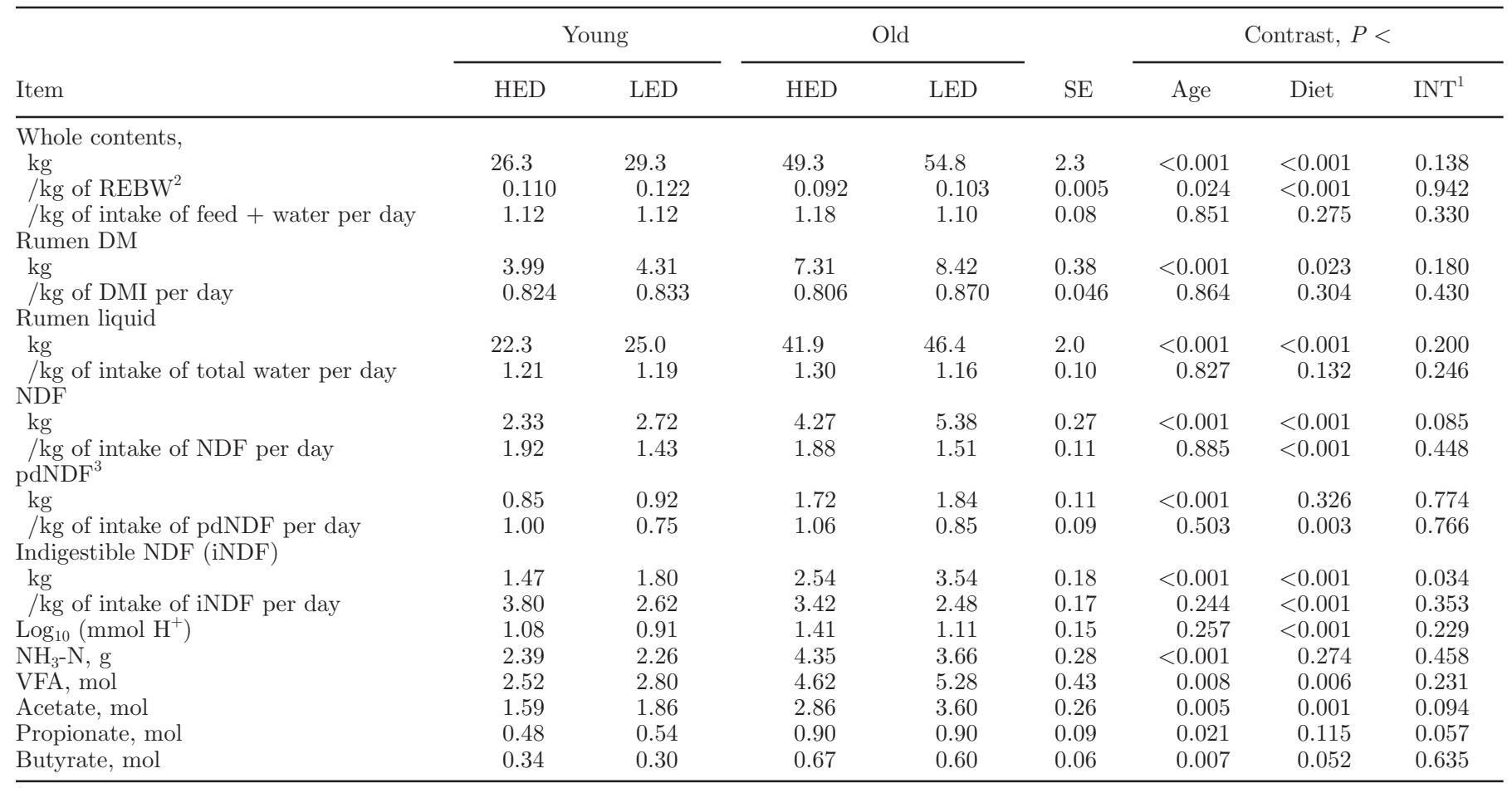

${ }^{1}$ Interaction between age and diet main effects.

${ }^{2}$ Rumen content empty BW.

${ }^{3}$ Potentially digestible NDF based on iNDF excretion.

ability. This occurred, however, without differences in VFA concentration for either diet or age group. Although rumen $\mathrm{pH}$ was reduced for HED, limiting the intake of HED blunted the $\mathrm{pH}$ reduction to a level that approximated what would be seen for typical lactating dairy cows fed an appropriately balanced TMR (Zebeli et al., 2008). This reduction in $\mathrm{pH}$, however, could be a significant contributing factor to the reduced nutrient digestibilities observed in heifers fed HED. The profile of rumen $\mathrm{pH}, \mathrm{VFA}$, and ammonia differed over time between diets; however, the mechanism for this effect cannot be determined from this study. The circadian

Table 5. Chemical component consumed, apparently digested, and apparent digestibility for young or old heifers limit-fed diets with high (HED) or low energy density (LED)

\begin{tabular}{|c|c|c|c|c|c|c|c|c|}
\hline Item & \multicolumn{2}{|c|}{ Young } & \multicolumn{2}{|c|}{ Old } & $\mathrm{SE}$ & \multicolumn{3}{|c|}{ Contrast, $P<$} \\
\hline $\mathrm{OM}$ & 4.58 & 4.89 & 8.58 & 9.13 & 0.08 & $<0.001$ & $<0.001$ & 0.004 \\
\hline $\mathrm{NDF}$ & 1.27 & 1.94 & 2.38 & 3.61 & 0.04 & $<0.001$ & $<0.001$ & $<0.001$ \\
\hline $\operatorname{pdNDF}^{2}$ & 0.88 & 1.24 & 1.63 & 2.19 & 0.05 & $<0.001$ & $<0.001$ & 0.019 \\
\hline Starch & 2.10 & 1.35 & 3.94 & 2.54 & 0.05 & $<0.001$ & $<0.001$ & $<0.001$ \\
\hline pdNDF & 0.70 & 1.02 & 1.21 & 1.69 & 0.05 & $<0.001$ & $<0.001$ & 0.047 \\
\hline Starch & 2.01 & 1.32 & 3.80 & 2.52 & 0.06 & $<0.001$ & $<0.001$ & $<0.001$ \\
\hline \multicolumn{9}{|c|}{ Chemical component digestibility, $\%$} \\
\hline $\mathrm{OM}$ & 77.4 & 72.5 & 76.0 & 70.6 & 0.9 & 0.150 & $<0.001$ & 0.781 \\
\hline NDF & 54.8 & 52.9 & 50.9 & 46.7 & 2.1 & 0.090 & 0.070 & 0.460 \\
\hline pdNDF & 79.2 & 82.4 & 74.2 & 77.0 & 1.6 & 0.038 & 0.016 & 0.880 \\
\hline Starch & 96.0 & 97.3 & 96.4 & 99.3 & 0.5 & 0.064 & $<0.001$ & 0.121 \\
\hline
\end{tabular}

${ }^{1}$ Interaction between age and diet main effects.

${ }^{2}$ Potentially digestible NDF based on indigestible NDF excretion. 
Table 6. Corn silage OM and NDF in situ digestion model parameter estimates for young or old heifers limit-fed diets with high (HED) or low energy density (LED) $)^{1}$

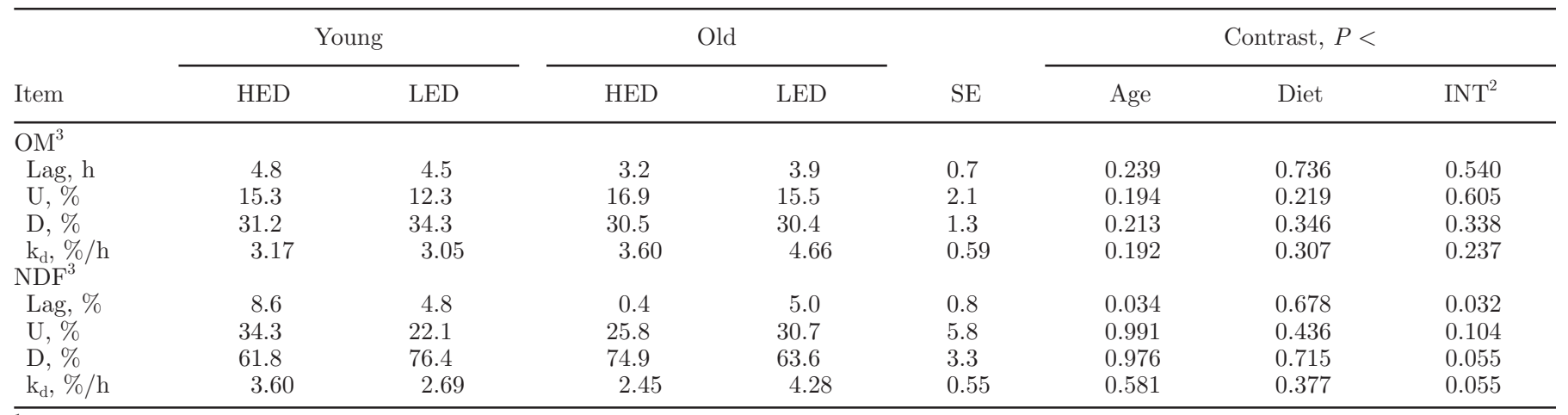

${ }^{1}$ Assessed with 4 heifers (2 young, 2 old) during adaptation time in periods 2 and 4 when treatment ration offered was the same as the previous periods.

${ }^{2}$ Interaction between age and diet main effects.

${ }^{3}$ Fitted with a mixed effects nonlinear model: OM or NDF remaining $=\mathrm{U}+\mathrm{D} e^{-\mathrm{kd}(t-\mathrm{Lag})}$, when $t>\mathrm{Lag}$, or $\mathrm{U}+\mathrm{D}$ when $t<\mathrm{Lag}$ with predicted parameter estimates of $\mathrm{U}=$ indigestible material at $t=\infty(\%), \mathrm{D}=$ potentially digestible pool $(\%), \mathrm{k}_{\mathrm{d}}=$ fractional digestion rate $(\% / \mathrm{h})$, Lag $=$ time before disappearance begins $(\mathrm{h})$.

pattern of dietary intake, rate of consumption, and feeding behavior was not measured in this study; however, anecdotally, heifer feeding behavior was consistent with the results reported by Kitts et al. (2011) in that heifers consumed HED in much less time than LED. Consistent with other studies (Rogers et al., 1979; Colucci et al., 1990), feeding LED increased the predicted rate of passage from the rumen. The greater rumen mass for heifers fed LED was primarily driven by the consumed mass of feed and water, as these expressed ratios were not different between diets or age groups. Considering the differences in rumen content mass for both diet and age group, VFA pool sizes were calculated from rumen liquid content and VFA concentration (Hall et al., 2015). This resulted in heifers fed LED having a greater pool size of VFA due to greater moles of acetate present in the rumen, likely because of the greater rumen amount of pdNDF that was digested in the rumen. It is interesting that propionate was not different because of the greater inclusion of starch in HED as has been shown previously (Bauman et al., 1971); however, it is important to note that, although pool sizes do account for differences in rumen volume that may be present across treatments, pool size is still only the accumulated balance of rates of production, conversion, absorption, and passage and may not adequately reflect production rates (Siciliano-Jones and Murphy, 1989).

Consistent with previous research (Blaxter et al., 1966; Moody et al., 2007; Zanton and Heinrichs, 2008) and expectation due to the greater increment of target gain to maintenance, young heifers retained a greater proportion of consumed or digested $\mathrm{N}$ than did old heifers. In fact, the mass of $\mathrm{N}$ retained did not differ between age groups. Apparent digestibility was not

Table 7. Digestion kinetics of NDF for young or old heifers limit-fed diets with high (HED) or low energy density (LED)

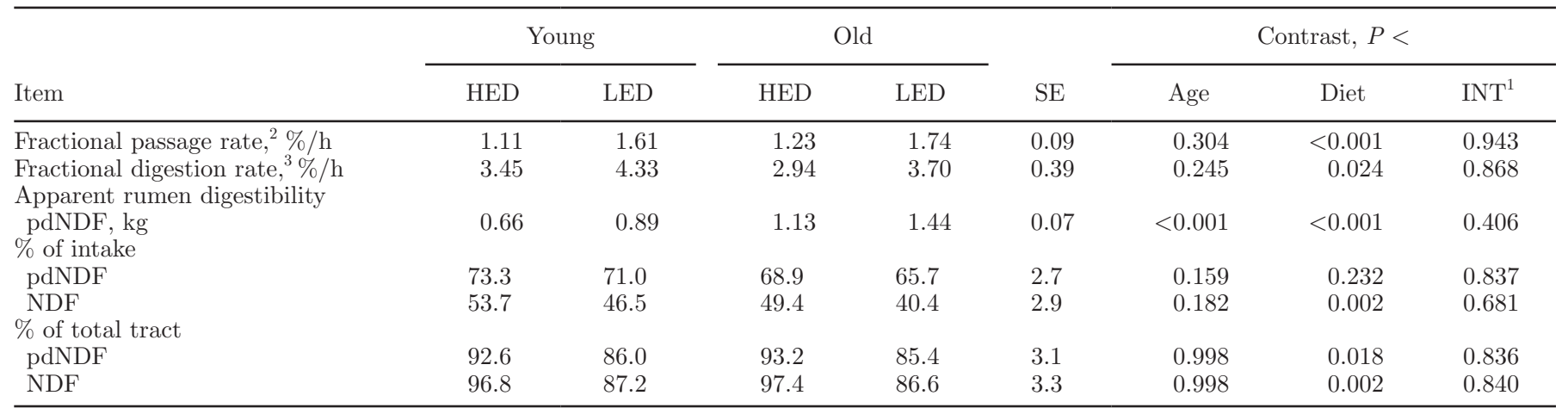

${ }^{1}$ Interaction between age and diet main effects.

${ }^{2}$ Based on indigestible NDF (iNDF) pool size and excretion rate.

${ }^{3}$ For NDF that is potentially digestible (pdNDF) based on iNDF excretion rate. 
Table 8. Nitrogen balance for young or old heifers limit-fed diets with high (HED) or low energy density (LED)

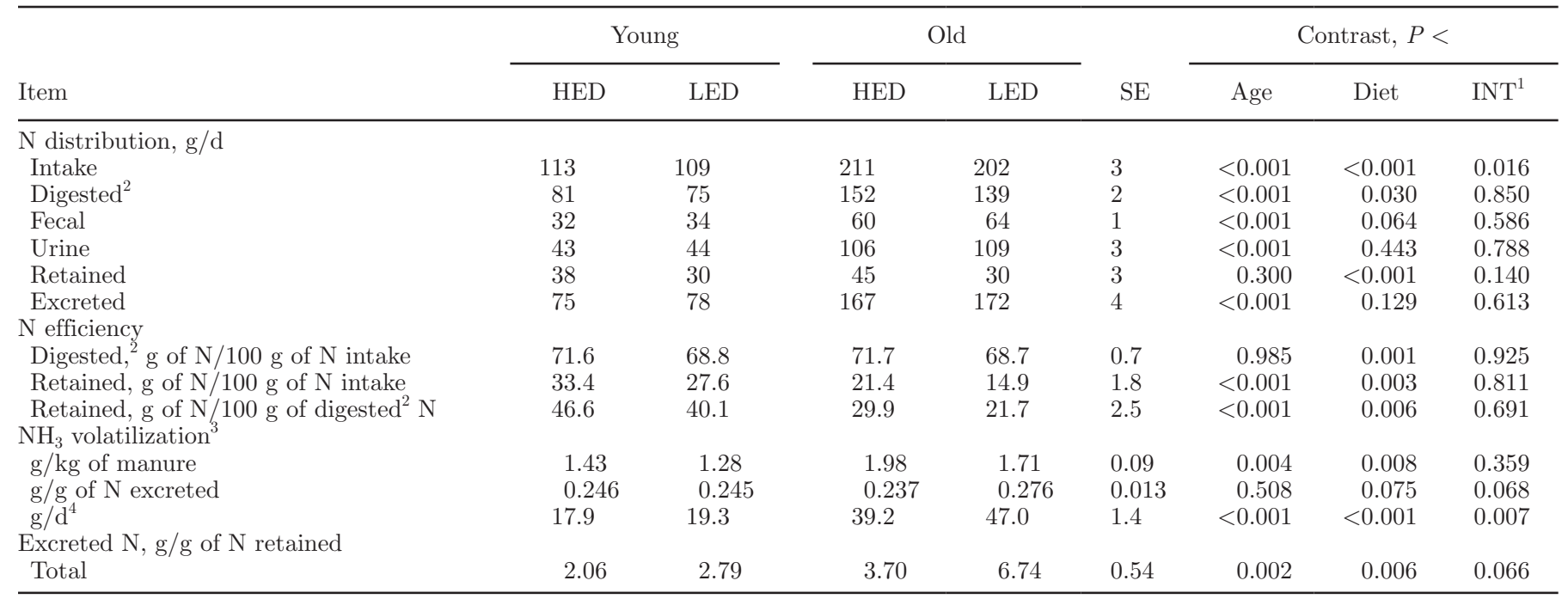

${ }^{1}$ Interaction between age and diet main effects.

${ }^{2}$ Apparent.

${ }^{3}$ Evaluated for $24 \mathrm{~h}$ using 200-g slurry of wet feces and urine combined in proportions reflecting amounts excreted.

${ }^{4}$ Calculated as $\mathrm{NH}_{3}$ volatilization $/ 24 \mathrm{~h}$ per $\mathrm{kg}$ of manure $\times$ total manure output.

different between age groups, so this difference was driven by an increased efficiency of postabsorptive metabolism for young heifers. Heifers fed HED retained proportionally more $\mathrm{N}$ than heifers fed LED due to the combined effects of greater $\mathrm{N}$ apparent digestibility and retention of apparently digested $\mathrm{N}$. These results differ from those reported by Zanton and Heinrichs (2009a), in which $\mathrm{N}$ retention efficiency did not differ for heifers fed high or low levels of forage with 4 levels of $\mathrm{N}$ intake until $\mathrm{N}$ intake was at its highest $(\sim 3 \mathrm{~g}$ of $\mathrm{N} / \mathrm{kg}$ of $\mathrm{BW}^{0.75}$ per day), which is greater than that fed in this experiment $\left(\sim 1.75 \mathrm{~g}\right.$ of $\mathrm{N} / \mathrm{kg}$ of $\mathrm{BW}^{0.75}$ per day). Greater apparent $\mathrm{N}$ digestibility for heifers fed HED is consistent with the results observed across all levels of $\mathrm{N}$ intake in Zanton and Heinrichs (2009a) and may be due to the lower DMI provided to these heifers to maintain isoenergetic intake, resulting in a lower excretion of metabolic fecal $\mathrm{N}$.
Zanton and Heinrichs (2008) reported the results of a literature analysis on the effects of $\mathrm{N}$ intake on $\mathrm{N}$ balance across ages and dietary conditions. An equation was presented for predicting $\mathrm{N}$ retention from $\mathrm{BW}, \mathrm{ME}$ intake, $\mathrm{N}$ intake, and DMI. Nitrogen retention in the current experiment for young heifers showed reasonably good consistency with predictions (HED: $38 \mathrm{~g}$ of N/d observed, $34 \mathrm{~g}$ of N/d predicted; LED: $30 \mathrm{~g}$ of N/d observed, $30 \mathrm{~g}$ of $\mathrm{N} / \mathrm{d}$ predicted), which were among the highest levels of $\mathrm{N}$ retention in that database. Nitrogen retention for old heifers, in contrast, was not close to predicted values and substantially higher than what would be expected (HED: $45 \mathrm{~g}$ of N/d observed, $18 \mathrm{~g}$ of N/d predicted; LED: $30 \mathrm{~g}$ of N/d observed, $15 \mathrm{~g}$ of $\mathrm{N} / \mathrm{d}$ predicted). The causes of this discrepancy are not apparent from the current experiment. Total collection methodology was consistent across age groups and is not anticipated to be a major contributor to this difference.

Table 9. Excreta output for young or old heifers limit-fed diets with high (HED) or low energy density (LED)

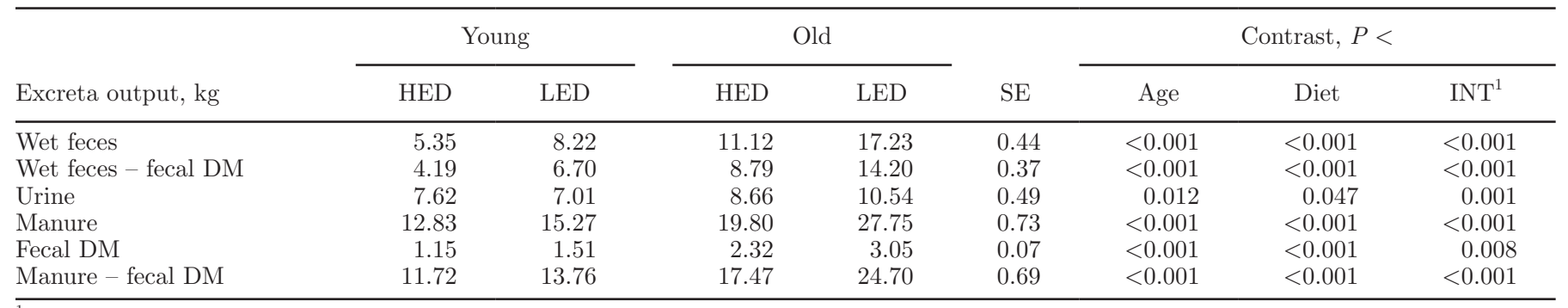

${ }^{1}$ Interaction between age and diet main effects. 
The database upon which the prediction equation was based did not have heifers with $\mathrm{BW}>500 \mathrm{~kg}$, so the use of this equation is strictly an extrapolation for the old heifers in this experiment; nevertheless, this high level of $\mathrm{N}$ retention would not be expected based on that database. No attempt was made to control or quantify secretions of reproductive activity in heifers (that were neither pregnant nor bred during the experiment). This could be a difference between age groups that would not be detectable based on the methods used in this experiment; however, the magnitude of the difference between observed and predicted would not likely be explained by this additional route of $\mathrm{N}$ loss. Scurf $\mathrm{N}$ losses were likewise not measured; however, using equations reported by the NRC (2001), scurf N would not contribute more than $4 \mathrm{~g}$ of $\mathrm{N} / \mathrm{d}$ in old heifers. Energy predictions could be a contributing factor to this difference; however, ME intake would have to be impossibly high to predict the level of $\mathrm{N}$ retention observed in old heifers. Overall, many factors likely contribute to the differences between higher observed $\mathrm{N}$ retention than predicted from the literature for old heifers that cannot be determined from the results of this experiment. More research on nutrient utilization is needed for older heifers between the ages of breeding and the prefresh period due to the mass of feed consumed and the lower efficiency of $\mathrm{N}$ utilization.

Ammonia volatilized from a combined subsample of feces and urine was greater on a daily basis for heifers fed the LED ration. Excreted $\mathrm{N}$ for old heifers fed LED tended to be more volatile, resulting in an interaction between diet and age in daily $\mathrm{NH}_{3}$ volatilization; this response was greatest in old heifers fed LED compared with young heifers fed LED. Overall $\mathrm{N}$ excretion was not different between diets, indicating that the excreted $\mathrm{N}$ effect was greater per unit $\mathrm{N}$ retained for heifers fed LED and for old heifers. The reasons for these differential responses are not known, although the literature would largely indicate no effect of energy density on $\mathrm{NH}_{3}$ volatilization from manure (Lascano et al., 2008; Zanton and Heinrichs, 2009a; Aguerre et al., 2011; Lascano and Heinrichs, 2011).

Total manure output was significantly greater for heifers fed LED than for those fed HED, and this was especially the case for the old heifers due to an interaction between diet and age group. The majority of the magnitude of this response could be attributed to water excreted with feces, as has been documented previously with limit-fed heifers (Zanton and Heinrichs, 2009a; Lascano and Heinrichs, 2011). Water consumption was strongly related to these excretions; thus, from the perspective of water input for the animal and waste handling, heifers fed HED appear to be more environmentally benign. It would be interesting to evaluate through a life cycle analysis the implications of limit feeding dairy heifers a HED diet on the entire dairy operation, including the implications of the source of nutrients, competition for nutrients with the lactating herd, management resources required for implementation, and environmental inputs and outputs associated with this nutritional management strategy.

\section{CONCLUSIONS}

Heifers limit-fed the high energy density diet had greater digestibility of dietary organic matter and lower excretion of manure. The efficiency of nitrogen retention was greater for heifers fed the high energy density diet and for younger heifers. These results support the concept of limit feeding higher energy density diets as a potential means to reduce manure excretion and increase nitrogen efficiency.

\section{ACKNOWLEDGMENTS}

This research was a component of and partially funded by funds from NC-2042: Management Systems to Improve the Economic and Environmental Sustainability of Dairy Enterprises.

\section{REFERENCES}

Aguerre, M. J., M. A. Wattiaux, J. M. Powell, G. A. Broderick, and C. Arndt. 2011. Effect of forage-to-concentrate ratio in dairy cow diets on emission of methane, carbon dioxide, and ammonia, lactation performance, and manure excretion. J. Dairy Sci. 94:3081-3093.

Allen, M. S., and D. R. Mertens. 1988. Evaluating constraints on fiber digestion by rumen microbes. J. Nutr. 118:261-270.

Association of Official Analytical Chemists. 1990. Official Methods of Analysis. 15th ed. Assoc. Off. Anal. Chem., Arlington, VA.

Bach Knudsen, K. E. 1997. Carbohydrate and lignin contents of plant materials used in animal feeding. Anim. Feed Sci. Technol. 67:319 338.

Bauman, D. E., C. L. Davis, and H. F. Bucholtz. 1971. Propionate production in the rumen of cows fed either a control or high-grain, low-fiber diet. J. Dairy Sci. 54:1282-1287.

Blaxter, K. L., J. L. Clapperton, and F. W. Wainman. 1966. Utilization of the energy and protein of the same diet by cattle of different ages. J. Agric. Sci. 67:67-75.

Chaney, A. L., and E. P. Marbach. 1962. Modified reagents for determination of urea and ammonia. Clin. Chem. 8:130-132.

Colucci, P. E., G. K. Macleod, W. L. Grovum, I. McMillan, and D. J. Barney. 1990. Digesta kinetics in sheep and cattle fed diets with different forage to concentrate ratios at high and low intakes. J. Dairy Sci. 73:2143-2156.

Dado, R. G., and M. S. Allen. 1995. Intake limitations, feeding behavior, and rumen function of cows challenged with rumen fill from dietary fiber or inert bulk. J. Dairy Sci. 78:118-133.

Grant, R. J., and D. R. Mertens. 1992. Influence of buffer pH and raw corn starch addition on in vitro fiber digestion kinetics. J. Dairy Sci. 75:2762-2768.

Hall, M. B., T. D. Nennich, P. H. Doane, and G. E. Brink. 2015. Total volatile fatty acid concentrations are unreliable estimators of treatment effects on ruminal fermentation in vivo. J. Dairy Sci. 98:3988-3999. 
Heinrichs, A. J., C. M. Jones, S. M. Gray, P. A. Heinrichs, S. A. Cornelisse, and R. C. Goodling. 2013. Identifying efficient dairy heifer producers using production costs and data envelopment analysis. J. Dairy Sci. 96:7355-7362.

Hoffman, P. C., C. R. Simson, and M. Wattiaux. 2007. Limit feeding of gravid Holstein heifers: Effect on growth, manure nutrient excretion, and subsequent early lactation performance. J. Dairy Sci. 90:946-954.

Jones, B., and M. G. Kenward. 2003. Design and Analysis of CrossOver Trials. 2nd ed. Chapman and Hall/CRC, London, UK.

Kitts, B. L., I. J. H. Duncan, B. W. McBride, and T. J. DeVries. 2011. Effect of the provision of a low-nutritive feedstuff on the behavior of dairy heifers limit fed a high-concentrate ration. J. Dairy Sci. 94:940-950.

Krishnamoorthy, U., T. V. Muscato, C. J. Sniffen, and P. J. Van Soest. 1982. Nitrogen fractions in selected feedstuffs. J. Dairy Sci. $65: 217-225$.

Lascano, G. J., and A. J. Heinrichs. 2011. Effects of feeding different levels of dietary fiber through the addition of corn stover on nutrient utilization of dairy heifers precision-fed high and low concentrate diets. J. Dairy Sci. 94:3025-3036.

Lascano, G. J., G. I. Zanton, M. L. Moody, P. A. Topper, E. F. Wheeler, and A. J. Heinrichs. 2008. Short communication: Effect of changing the ratio of forage to concentrate on ammonia emissions by dairy heifers. J. Dairy Sci. 91:4301-4306.

Maulfair, D. D., M. Fustini, and A. J. Heinrichs. 2011. Effect of varying total mixed ration particle size on rumen digesta and fecal particle size and digestibility in lactating dairy cows. J. Dairy Sci. 94:3527-3536.

Moody, M. L., G. I. Zanton, J. M. Daubert, and A. J. Heinrichs. 2007. Nutrient utilization of differing forage-to-concentrate ratios by growing Holstein heifers. J. Dairy Sci. 90:5580-5586.

Mould, F. L., E. R. Ørskov, and S. O. Mann. 1983. Associative effects of mixed feeds. I. Effects of type and level of supplementation and the influence of the rumen fluid $\mathrm{pH}$ on cellulolysis in vivo and dry matter digestion of various roughages. Anim. Feed Sci. Technol. $10: 15-30$

Murphy, T. A., S. C. Loerch, and F. E. Smith. 1994. Effects of feeding high-concentrate diets at restricted intakes on digestibility and nitrogen metabolism in growing lambs. J. Anim. Sci. 72:1583-1590.

NRC. 2001. Nutrient Requirements of Dairy Cattle. 7th rev. ed. National Academies Press, Washington, DC.

Reynolds, C. K., H. F. Tyrrell, and P. J. Reynolds. 1991. Effects of diet forage-to-concentrate ratio and intake on energy metabolism in growing beef heifers: Whole body energy and nitrogen balance and visceral heat production. J. Nutr. 121:994-1003.
Rogers, J. A., B. C. Marks, C. L. Davis, and J. H. Clark. 1979. Alteration of rumen fermentation in steers by increasing rumen fluid dilution rate with mineral salts. J. Dairy Sci. 62:1599-1605.

SAS Institute. 2013. SAS User's Guide: Statistics. Version 9.4. SAS Inst. Inc., Cary, NC.

Siciliano-Jones, J., and M. R. Murphy. 1989. Production of volatile fatty acids in the rumen and cecum-colon of steers as affected by forage: concentrate and forage physical form. J. Dairy Sci. $72: 485-492$.

Tozer, P. R., and A. J. Heinrichs. 2001. What affects the costs of raising replacement dairy heifers: A multiple-component analysis. J. Dairy Sci. 84:1836-1844.

Van Soest, P. J., J. B. Robertson, and B. A. Lewis. 1991. Methods for dietary fiber, neutral detergent fiber, and nonstarch polysaccharides in relation to animal nutrition. J. Dairy Sci. 74:3583-3597.

Waldo, D. R., L. W. Smith, and E. L. Cox. 1972. Model of cellulose disappearance from the rumen. J. Dairy Sci. 55:125-129.

Yang, C.-M. J., and G. A. Varga. 1989. Effect of three concentrate feeding frequencies on rumen protozoa, rumen digesta kinetics, and milk yield in dairy cows. J. Dairy Sci. 72:950-957.

Zanton, G. I., M. T. Gabler, and A. J. Heinrichs. 2007. Manipulation of soluble and rumen-undegradable protein in diets fed to postpubertal dairy heifers. J. Dairy Sci. 90:978-986.

Zanton, G. I., and A. J. Heinrichs. 2005. Meta-analysis to assess effect of prepubertal average daily gain of Holstein heifers on firstlactation production. J. Dairy Sci. 88:3860-3867.

Zanton, G. I., and A. J. Heinrichs. 2007. The effects of controlled feeding of a high-forage or high-concentrate ration on heifer growth and first-lactation milk production. J. Dairy Sci. 90:3388-3396.

Zanton, G. I., and A. J. Heinrichs. 2008. Analysis of nitrogen utilization and excretion in growing dairy cattle. J. Dairy Sci. 91:15191533.

Zanton, G. I., and A. J. Heinrichs. 2009a. Digestion and nitrogen utilization in dairy heifers limit-fed a low or high forage ration at four levels of nitrogen intake. J. Dairy Sci. 92:2078-2094.

Zanton, G. I., and A. J. Heinrichs. 2009b. Evaluation of modeling procedure for fitting in situ feed degradation profiles. J. Anim. Sci. $87: 2080-2088$

Zanton, G. I., and A. J. Heinrichs. 2010. Short communication: Analysis of milk yield and composition for dairy heifers limit-fed lower forage diets during the rearing period. J. Dairy Sci. 93:4730-4734.

Zebeli, Q., J. Dijkstra, M. Tafaj, H. Steingass, B. N. Ametaj, and W. Drochner. 2008. Modeling the adequacy of dietary fiber in dairy cows based on the responses of ruminal $\mathrm{pH}$ and milk fat production to composition of the diet. J. Dairy Sci. 91:2046-2066. 